\title{
REVISTA BRASILEIRA DE CLIMATOLOGIA NORMAS E INSTRUÇÕES PARA PUBLICAÇÃO
}

A Revista Brasileira de Climatologia, instrumento de divulgação científica da Associação Brasileira de Climatologia, publica artigos científicos originais, notas técnicas, revisões bibliográficas, artigos especiais da área de Climatologia, com a condição de que sejam inéditos.

1. Os artigos especiais serão submetidos sob convite do Conselho Editorial. Nos outros tipos de publicação, ao menos um dos autores do trabalho deverá ser, preferencialmente, sócio da Associação Brasileira de Climatologia.

2. Os trabalhos serão submetidos via eletrônica, digitados em formato compatível com Word ou Open Office Writer, num dos 4 idiomas: português, espanhol, inglês e francês, em folha A4 com margens de $2,5 \mathrm{~cm}$, fonte Verdana 10, espaço simples, sem recuos. O máximo de páginas será de 20 (vinte), incluídos tabelas, gráficos e ilustracões. Todos os artigos submetidos devem conter Resumo e palavras-chave em portuquês, e Abstract e Key-words em inglês; para os textos em francês ou espanhol, conter também os résumés e mots-clefs, e ou resumen e palavras-claves, respectivamente.

3. O trabalho submetido como artigo, deverá conter os seguintes tópicos: Título (em português, espanhol, inglês ou francês); Resumo (máximo 2000 caracteres) e Palavras-chave (máximo 5 palavras) em português e inglês (além do espanhol e francês se escrito netas línguas); Introdução com Revisão da Literatura e Objetivos; Material e métodos; Resultados e Discussão; Conclusões (ou combinação destes últimos), Agradecimentos, quando houver, e Referências Bibliográficas. Não há necessidade desta subdivisão para as notas e revisões, mas elas devem conter, obrigatoriamente, um pequeno resumo e abstract.

4. Identificação da autoria: SOBRENOME, Nome dos autores, seguido do endereço eletrônico, Titulação, Vinculação Institucional. Exemplo:

MENDONÇA, Francisco - chico@ufpr.br

Doutor em Geografia - Laboclima/UFPR (Brasil)

5. As citações dos autores no texto deverão ser feitas com letras minúsculas seguidas do ano de publicação entre parêntese e em letras maiúsculas se a citação estiver entre parentes, conforme exemplos:

O balanço hídrico foi calculado segundo o método de Thortnthwaite e Mather (1957)

........enquanto que em água pode representar 100\% (JARVIS, 1975).

6. As Referências Bibliográficas deverão ser apresentadas de acordo ABNT, como nos exemplos:

CAMARGO, A. P. de. Contribuição para a determinação da evapotranspiração potencial no Estado de São Paulo, Bragantia, Campinas, v. 21, n. 12, p, 163-213, 1962.

OMETTO, J. C. Bioclimatologia vegetal. São Paulo: Ceres, 1981. 400 p.

COCHRAN, W. G. The stimation of sample sign. In: Sampling Techniques. 3« ed. Nova York: John Willey, 1997, Cap. 4 p. 72-90.

7. As tabelas deverão ser numeradas com algarismos arábicos, com cabeçalho ou legenda explicativas na sua parte superior e construídas de modo a serem inteligíveis. Linhas horizontais devem aparecer para separar o título do cabeçalho e este do conteúdo, além de uma linha no final da tabela. Linhas verticais não devem ser usadas.

8. Desenhos, gráficos e fotografias serão denominados Figuras, tendo o número de ordem em algarismos arábicos e o título na sua parte inferior. Todas deverão estar em formato digital, preferencialmente no formato JPG, em resolução adequada ao tamanho da imagem. Não serão aceitas figuras repetitivas de tabelas.

9. A critério dos editores, os trabalhos que não se enquadrarem na área de Climatologia, não serão aceitos e devolvidos ao(s) autor(es), sem passar pelo trâmite editorial.

10. Na submissão, o(s) autor(es) deverá (ão) deixar claro o tipo de publicação (artigo, nota técnica ou revisão bibliográfica) que deseja $(\mathrm{m})$ para o trabalho.

11. Os conceitos e afirmações contidos nos artigos serão de inteira responsabilidade do(s) autor(es), mas o Conselho Editorial se resguarda o direito de sugerir alterações.

\section{Objetivos da RBClima}

A Revista Brasileira de Climatologia é o meio de divulgação da produção cientifico-técnica atinente à climatologia vinculado à ABClima - Associação Brasileira de Climatologia, entidade sem fins lucrativos. O objetivo da revista é a divulgação de artigos inéditos produzidos por estudantes, pesquisadores e docentes que atuam na área de Climatologia - Geografia, Meteorologia, Ecologia, Agronomia, Engenharia, Arquitetura, etc. Além da pretensão de ser um veículo de divulgação do conhecimento e 
informação, propõe-se a estimular a produção científica dos estudiosos da climatologia e evidenciar o estado da arte deste campo do conhecimento.

\title{
Conselho Editorial:
}

Ana Maria de P. M. Brandão (UFRJ / Rio de Janeiro)

Ana Monteiro (Univ. do Porto / Porto - Portugal)

Anderson Luís Hebling Christofoletti/UNESP*

André Geraldo Berezuk/UFGD*

Cássio Arthur Wollmann (UFSM / Santa Maria-RS)*

Cleusa Zamparoni (UFMT / Cuiabá - MT)

Deise Ely (UEL / Londrina - PR)*

Denise Maria Sette (UFMT / Rondonópolis - MT)*

Edson Cabral (PUC-SP / São Paulo-SP)*

Edson Soares Fialho (UFV / Viçosa-MG)*

Emerson Galvani (USP / São Paulo-SP)*

Ercília Torres Stenke (UNB / Brasília-DF)*

Érika Collishon (UFPel / Pelotas-RS)*

Francisco Mendonça (UFPR/Curitiba-PR)*

Helena Ribeiro (FSP/USP/ São Paulo-SP)

Hugo Romero (Univ. do Chile / Santiago - Chile)

Javier Martin-Vide (Univ. de Barcelona /Espanha)

João Afonso Zavattini (UNESP / Rio Claro-SP)*

João Lima Sant'Anna Neto (UNESP / Pres. Prudente-SP)

Josefa Eliane S. de Siqueira Pinto (UFS / Aracajú-SE)*

José Bueno Conti (USP / São Paulo/SP)*

Lisana Katia Schmitz / UFPR*

Luci Hidalgo Nunes (UNICAMP / Campinas-SP)*

Magaly Mendonça (UFSC / Florianópolis-SC)

Maria Cristina Valenzuela (UNRC / Argentina)

Maria Elisa Zanella (UFC / Fortaleza-CE)

Marta Celina Linhares Sales (UFC / Fortaleza-CE)*

Miriam Ramos Gutjahr (IG / SMA / São Paulo-SP)

Nelson Jesus Ferreira (CPTEC-INPE/S.J. dos Campos)

Pietro Ceccato (Columbia University/E.U.A.)*

Ranyére Silva Nóbrega (UFPE - Pernambuco)*

Sandra Elisa Contri Pitton (UNESP / Rio Claro-SP)

Tereza Reyna Trujillo (UNAM / México)

Vincent Dubreuil (Univ. de Rennes2 / Rennes/França)*

Washington Luiz Assunção (UFU / Uberlândia-MG)

Wilfred Endlicher (Humboldt Universität /Alemanha)*

Zilda de Fátima Mariano (UFG / Jataí-GO)

*Avaliadores dos textos deste número

\author{
Pareceristas Ad Hoc atuantes na avaliação dos textos da RBClima-17 \\ Cassia Castro (UFJF) \\ Fabio Sanches (UFTM) \\ Gustavo Armani (IG/SP) \\ Marcos Norberto Boin (UNOESTE) \\ Maria Cleide Baldo (UNESP) \\ Natacha Aleixo (UEA) \\ Rafael Rodrigues da Franca (UFRO) \\ Renato Tavares (IG/SP) \\ Vicentina Socorro Anunciação (UFMS) \\ Victor Assunção Borsato (UNESPAR) \\ Wellington Lopes Assis (UFMG)
}

